\title{
Mental and Seizure Manifestations in Relation to Brain Tumors A Statistical Study
}

\author{
A. GUVVENER, B. K. BAGCHI, K. A. KOOI AND H. D. CALHOUN
}

The Electroencephalographic Laboratory, Neuropsychiatric Institute, University of Michigan Medical Center, Ann Arbor, Mich. (U.S.A.)

\section{INTRODUCTION}

It is well known that mental or behavioral changes and seizures occur in some phases of the development of many tumors. Many investigators in reporting large series ( 300 or over) have given the frequency of the clinical manifestations and their relationships to areas and types of tumors $(2,4,5,9,10,12-15,17,20,22,24,27,31)$. It is not always clear why some tumors produce the above mentioned manifestations and others of the same type, same location and about the same size do not. We thought it might be of interest to make a statistical evaluation of the interrelationships between three variables, tumor location, tumor type, increased intracranial pressure in respect to mental and seizure manifestations. In the literature these relationships are not always clearly given. These might have some bearing on the mechanism of the clinical changes.

\section{MATERIAL AND METHODS}

Out of 901 brain tumor entries in the EEG Laboratory file with EEG and clinical data only 326 have been selected for this report. The excluded ones are the following: all 359 brain tumor entries before 1950, in addition to a total of 167 metastatic, brain stem and posterior fossa tumors, and 49 tumors with incomplete clinical and EEG information. Out of the accepted 326 cases gross and microscopic autopsy findings were available in 62 . The location of the remaining tumors was judged from recorded clinical, EEG, radiological and surgical data. Except for discrete and some deep midline tumors like craniopharyngiomas and olfactory groove meningiomas, a certain amount of location inaccuracies was inevitable though this probably did not seriously affect the statistical relationships. This was evidently a problem in all reported series

Presented at the Annual Meeting of the American Epilepsy Society, New York, December 5, 1963. Supported in part by Grant No. B1805 (C) from USPHS (NINDB).

Permanent address of Dr. Adnan Güvener: Department of Neurology, Faculty of Medicine, University of Ankara, Ankara (Turkey). 
whether or not clearly stated. 189 were male, 137 were female. The age distribution was as follows: 51 cases within 10 years, 13 cases between 10 and 20,19 cases between 20 and 30,219 cases between 30 and 60 and 60 cases over 60 years.

Tumors were divided into the following types (Table I): glioblastoma multiforme, astrocytoma and oligodendroglioma, meningioma, pituitary adenoma, craniopharyngioma, and miscellaneous tumors including neuroblastoma (6), ependymoma (5), spongioblastoma, ectopic pinealoma, optic glioma, two each, teratoma, neuroastrocytoma, astroblastoma, ganglioneuroma, melanoblastoma, chordoma, one each. Astrocytomas, grade III and IV, were included under glioblastoma multiforme. Tumors were also divided by location into three broad categories (Table II).

(A) Hemispheric tumors in one or more lobes invading or touching the white matter. These are subdivided (Table III) into frontal, temporal, parietal, frontotemporal, temporo-parietal, motor-parietal, parieto-occipital, temporo-frontal (greater share being in temporal than in fronto-temporal subdivision), parieto-temporal and multilobar (more than two lobes). No pure occipital tumor was encountered in this series.

(B) Hemispheric tumors with deep extension involving any of the above subdivisions plus corpus callosum, lateral ventricle, third ventricle, basal ganglia, thalamus or other deep regions, on one or both sides (Table IV).

(C) Deep midline and paramidline tumors primarily involving pituitary region, third ventricle, optic chiasm, optic nerves, thalamus, hypothalamus or with hypothalamic invasion, suprasellar region with or without optic chiasm and inferior frontal involvement, basal ganglia, corpus callosum, lateral ventricle, olfactory groove, sphenoid ridge or any combination of two or more regions (Table V). As mentioned before, posterior fossa, midbrain and metastatic tumors were not considered.

The sizes of the infiltrating tumors that did not have necropsy could not be accurately judged. However, except for a few intrasellar pituitary tumors without superior extension, most of them were of moderate to large size and probably never less than $1 \times 1 \times 1 \mathrm{~cm}$.

Definite mental or behavioral changes related to tumors usually included more than one of the following clinical symptoms: disorientation (39), confusion (59), psychotic behavior (10), memory impairment (77), organic brain syndrome (11), lability in affect (15), lethargy (41), personality change including garrulousness, untidiness, bizarre behavior, etc. (46), depression (12), somnolence (2), euphoria (5), decrease of attention span (4). These symptoms were not considered mutually exclusive nor are the number of patients showing them as entered here additive. Different designations originally used by attending physicians for the same symptoms are retained at the risk of seeming duplication. The mental or behavioral changes were insidious and, from history, usually covered a period of a few weeks to many months. Some of them were accentuation of premorbid personality. Obvious minor mental reactions to the illness were disregarded. In children only marked changes were noted.

Seizures included grand mal, petit mal, motor or sensory Jacksonian with or without adversive component, vague "spells", if recurrent, "temporal lobe" seizure 
with subjective manifestations of all varieties and modalities including olfactory, auditory, gustatory, visual formed hallucinations, epigastric sensation, deja vu, fear, rage or anxiety attacks without sufficient provocation. Being a statistical study fine nuances of clinical manifestations were not emphasized although relatively complete clinical information was available. Psychomotor seizure involving only bizarre or inappropriate motor behavior with confusion and subsequent amnesia was included under "temporal lobe" seizure. In some temporal lobe tumors mental aberration and temporal lobe seizure phenomenon interdigitated and it was difficult to tease one from the other.

Increased intracranial pressure was supposed to be present when there was papilledema (131), high cerebrospinal fluid pressure (40) (over $180 \mathrm{~mm}$ of water), separation of sutures of the skull in children (7), extrasellar erosion (16) or marked pressure at the dura at operation (74). Fifty-three patients had more than one indication of increased intracranial pressure.

Seventy-one $\chi^{2}$ calculations were done between the different groups and only significant relationships were entered on the tables.

\section{RESULTS}

Table I gives a list of the types and numbers of tumors. It also indicates that mental changes and seizures occurred $58.6 \%$ and $48.1 \%$ respectively, considering the total group, that is, roughly in about half of them regardless of location or other factors. The range of percentages under these two categories is, however, very wide, from

TABLE I

SEIZURE, MENTAL CHANGE, INCREASED INTRACRANIAL PRESSURE IN DIFFERENT TYPES OF TUMORS

\begin{tabular}{|c|c|c|c|c|c|c|c|c|}
\hline \multirow[t]{2}{*}{ Group } & \multirow[t]{2}{*}{ Type } & \multirow{2}{*}{$\begin{array}{l}\text { Num- } \\
\text { ber }\end{array}$} & \multicolumn{2}{|c|}{$\begin{array}{l}\text { Mental } \\
\text { change }\end{array}$} & \multicolumn{2}{|c|}{ Seizure } & \multicolumn{2}{|c|}{$\begin{array}{c}\text { Increased } \\
\text { intracranial } \\
\text { pressure }\end{array}$} \\
\hline & & & $\begin{array}{c}\text { Num- } \\
\text { ber }\end{array}$ & $\%$ & $\begin{array}{c}\text { Num- } \\
\text { ber }\end{array}$ & $\%$ & $\begin{array}{c}\text { Num- } \\
\text { ber }\end{array}$ & $\%$ \\
\hline A & Glioblastoma & 111 & 79 & 71.2 & 39 & 35.1 & 76 & 68.5 \\
\hline \multirow[t]{2}{*}{ B } & Astrocytoma and & & & & & & & \\
\hline & oligodendroglioma & 92 & 49 & 53.3 & 68 & 73.9 & 54 & 58.7 \\
\hline C & Meningioma & 73 & 38 & 52.1 & 39 & 53.4 & 40 & 54.8 \\
\hline $\mathbf{D}$ & Pituitary & 17 & 9 & 52.9 & 2 & 11.8 & 3 & 17.6 \\
\hline E & Craniopharyngioma & 10 & 3 & 30.0 & 0 & 0.0 & 7 & 70.0 \\
\hline \multirow[t]{7}{*}{$\mathbf{F}$} & Miscellaneous & 23 & 13 & 56.5 & 9 & 34.8 & 14 & 60.9 \\
\hline & Total & $\overline{326}$ & $\overline{191}$ & $\overline{58.6}$ & $\overline{157}$ & $\overline{48.1}$ & $\overline{194}$ & $\overline{59.5}$ \\
\hline & $P$ & & \multirow{5}{*}{\multicolumn{2}{|c|}{$\begin{array}{l}\text { A vs. B } 0.01^{*} \\
\text { A vs. C } 0.01\end{array}$}} & \multirow{5}{*}{\multicolumn{2}{|c|}{$\begin{array}{l}\text { A } v s . \text { B } 0.001^{*} \\
\text { A vs. C } 0.025 \\
\text { B } v s . \text { C } 0.01 \\
\text { B } v s . \text { D } 0.01 \\
\text { C vs. D } 0.01\end{array}$}} & & \\
\hline & & & & & & & & \\
\hline & & & & & & & & \\
\hline & & & & & & & & \\
\hline & & & & & & & & \\
\hline
\end{tabular}

* A vs. astrocytoma (67) in respect to mental change: $P 0.01$; A vs. oligodendroglioma (25) in respect to seizure: $P 0.001 ; \mathrm{A} v s$, astrocytoma in respect to seizure: $P 0.001$. 
0 to $73.0 \%$ and may be misleading. When different tumor types are considered for mental changes it is found that glioblastoma multiformes are likely to produce more mental changes as a group than either astrocytomas or oligodendrogliomas separately, or combined. The level of confidence in these three instances is $P<0.01$. Differences between any other tumor types for mental changes are not statistically significant.

Considering the seizure phenomena, instead of 3 there are 7 statistically significant relationships between tumor types, and also the situation is reversed. Statistically astrocytomas, oligodendrogliomas, taken together or separately, are likely to cause more seizures of any kind than glioblastoma multiforme. This also holds good for meningiomas as against glioblastoma multiforme. A combined astrocytoma and oligodendroglioma group has a higher incidence of seizure than the pituitary group, and interestingly, more than meningiomas. And meningiomas are apparently more effective in producing seizures than pituitary tumors, although the latter is a much smaller sample. Astrocytomas alone are also apt to be ahead of glioblastomas in this respect. Craniopharyngiomas are too few (10) to be included in the statistical calculation, though none of them produced seizures. The miscellaneous tumors were too varied in type for meaningful comparison with other tumors.

One realizes that significant statistical relationship between two variables does not mean that in individual cases this relationship may be always present or positive. That is, it is possible there may be no relationship between such cases. For this reason and in recognition of the complexity of factors in cerebral physiology it may be worthwhile to investigate what role increased intracranial pressure plays in the production of the above-mentioned clinical changes.

Again looking at Table I it appears that $59.5 \%$ of the total group had increased intracranial pressure that is, about the same percentage as those having mental changes and slightly more than having seizures. Is increased intracranial pressure then responsible in the main for mental changes and seizure? Is that the common factor? Intertype calculation does not bear this out. That is to say, there is no statistically

TABLE II

BROAD BRAIN TUMOR LOCATION CATEGORIES AND SEIZURE, MENTAL CHANGE AND INTRACRANIAL PRESSURE

\begin{tabular}{|c|c|c|c|c|c|c|c|c|}
\hline \multirow[t]{2}{*}{ Group } & \multirow[t]{2}{*}{ Location } & \multirow{2}{*}{$\begin{array}{c}\text { Num- } \\
\text { ber }\end{array}$} & \multicolumn{2}{|c|}{$\begin{array}{l}\text { Mental } \\
\text { change }\end{array}$} & \multicolumn{2}{|c|}{ Seizure } & \multicolumn{2}{|c|}{$\begin{array}{c}\text { Increased } \\
\text { intracranial } \\
\text { pressure }\end{array}$} \\
\hline & & & $\begin{array}{c}\text { Num- } \\
\text { ber }\end{array}$ & $\%$ & $\begin{array}{c}\text { Num- } \\
\text { ber }\end{array}$ & $\%$ & $\begin{array}{c}\text { Num- } \\
\text { ber }\end{array}$ & $\%$ \\
\hline \multirow{5}{*}{$\begin{array}{l}\text { A } \\
\text { B } \\
\text { C }\end{array}$} & \multirow{3}{*}{$\begin{array}{l}\text { Hemispheric } \\
\text { Hemispheric and deep } \\
\text { Deep midline and } \\
\quad \text { paramidline }\end{array}$} & 179 & 102 & 57.0 & 99 & 55.3 & 107 & 59.8 \\
\hline & & 64 & 42 & 65.6 & 38 & 59.4 & 46 & 71.9 \\
\hline & & 83 & 47 & 56.6 & 20 & 24.1 & 41 & 49.4 \\
\hline & \multirow{2}{*}{$\begin{array}{l}\text { Total } \\
P\end{array}$} & 326 & 191 & 58.6 & 157 & 48.1 & 194 & 59.5 \\
\hline & & & & & \multicolumn{2}{|c|}{$\begin{array}{l}\text { A vs. C } 0.001 \\
B \text {. C } 0.001\end{array}$} & B vs. C 0.01 & \\
\hline
\end{tabular}


TABLE

SEIZURE, MENTAL CHANGE, INCREASED INTRACRANIAL PRESSURE

\begin{tabular}{|c|c|c|c|c|c|c|c|c|c|c|c|c|}
\hline & \multirow{2}{*}{\multicolumn{2}{|c|}{$\frac{\text { Frontal }(F)}{\text { IICP }}$}} & \multirow{2}{*}{\multicolumn{2}{|c|}{$\frac{\text { Temporal }(T)}{I I C P}$}} & \multirow{2}{*}{\multicolumn{2}{|c|}{$\frac{\text { Parietal }(P)}{I I C P}$}} & \multirow{2}{*}{\multicolumn{2}{|c|}{$\frac{F-T}{I I C P}$}} & \multirow{2}{*}{\multicolumn{2}{|c|}{$\begin{array}{c}T-P \\
I C P\end{array}$}} & \multirow{2}{*}{\multicolumn{2}{|c|}{$\frac{\text { Motor-P }}{I I C P}$}} \\
\hline & & & & & & & & & & & & \\
\hline & yes & no & yes & no & yes & no & yes & no & yes & no & yes & no \\
\hline Seizure & 6 & 8 & 4 & 6 & 6 & 5 & 1 & 0 & 3 & 1 & 3 & 7 \\
\hline Mental change & 14 & 4 & 2 & 2 & 4 & 3 & 3 & 1 & 4 & 2 & 5 & 4 \\
\hline \multirow{2}{*}{\multicolumn{13}{|c|}{$\begin{array}{l}\text { Seizure and mental } \\
\text { change }\end{array}$}} \\
\hline & 6 & 7 & 6 & 5 & 3 & 1 & 1 & 0 & 3 & 0 & 3 & 3 \\
\hline \multirow[t]{3}{*}{ None } & 4 & 0 & 1 & 0 & 4 & 5 & $\mathbf{0}$ & 0 & $\mathbf{0}$ & 0 & 3 & 0 \\
\hline & 30 & $\overline{19}$ & $\overline{13}$ & $\overline{13}$ & 17 & $\overline{14}$ & 5 & $\overline{1}$ & $\overline{10}$ & $\overline{3}$ & $\overline{14}$ & $\overline{14}$ \\
\hline & \multicolumn{2}{|c|}{49} & \multicolumn{2}{|c|}{26} & \multicolumn{2}{|c|}{31} & \multicolumn{2}{|c|}{6} & \multicolumn{2}{|c|}{13} & \multicolumn{2}{|c|}{28} \\
\hline
\end{tabular}

TABLE

SEIZURE, MENTAL CHANGE, INCREASED INTRACRANIAL PRESSURE

\begin{tabular}{|c|c|c|c|c|c|c|c|c|c|c|c|c|}
\hline & \multirow{2}{*}{\multicolumn{2}{|c|}{$\begin{array}{c}\text { Frontal }(F) \\
I C P\end{array}$}} & \multirow{2}{*}{\multicolumn{2}{|c|}{$\frac{\text { Temporal }(T)}{I I C P}$}} & \multirow{2}{*}{\multicolumn{2}{|c|}{$\frac{\text { Parietal }(P)}{\text { IICP }}$}} & \multirow{2}{*}{\multicolumn{2}{|c|}{$\begin{array}{c}F-T \\
I C P\end{array}$}} & \multirow{2}{*}{\multicolumn{2}{|c|}{$\frac{T-P}{I I C P}$}} & \multirow{2}{*}{\multicolumn{2}{|c|}{$\frac{\text { Motor-P }}{I I C P}$}} \\
\hline & & & & & & & & & & & & \\
\hline & yes & no & yes & no & yes & no & yes & no & yes & no & yes & no \\
\hline Seizure & 3 & 1 & 3 & 2 & 1 & $\mathbf{0}$ & 0 & 1 & 2 & 1 & 0 & 0 \\
\hline Mental change & 5 & 0 & 3 & $\mathbf{0}$ & 1 & $\mathbf{0}$ & 2 & 0 & 2 & 0 & 1 & 0 \\
\hline Seizure and mental & & & & & & & & & & & & \\
\hline change & 8 & 3 & 3 & 1 & 0 & 1 & 0 & 0 & 2 & 0 & 1 & 0 \\
\hline None & 0 & 1 & 1 & $\mathbf{0}$ & 1 & 1 & 0 & $\underline{0}$ & 1 & 0 & 0 & 0 \\
\hline Total & $\overline{16}$ & 5 & $\overline{10}$ & 3 & 3 & $\overline{2}$ & 2 & 1 & 7 & 1 & 2 & $\overline{0}$ \\
\hline & & & & & & & & & & 8 & & \\
\hline
\end{tabular}

TABLE

SEIZURE, MENTAL CHANGE, INCREASED INTRACRANIAL PRESSURE|

\begin{tabular}{|c|c|c|c|c|c|c|c|c|c|c|c|c|}
\hline & \multirow{2}{*}{\multicolumn{2}{|c|}{$\begin{array}{c}\text { (A) } \\
\text { Olfactory } \\
+ \text { sphenoid } \\
\text { meningioma }\end{array}$}} & \multirow{2}{*}{\multicolumn{2}{|c|}{$\begin{array}{c}\begin{array}{c}\text { (B) } \\
\text { Suprasellar }\end{array} \\
I I C P\end{array}$}} & \multirow{2}{*}{\multicolumn{2}{|c|}{$\begin{array}{c}\begin{array}{c}\text { (C) } \\
\text { Pituitary }\end{array} \\
\text { IICP }\end{array}$}} & \multirow{2}{*}{\multicolumn{2}{|c|}{$\begin{array}{c}\text { (D) } \\
\begin{array}{c}\text { Hypothal. } \\
\text { invasion }\end{array} \\
\text { IICP }\end{array}$}} & \multirow{2}{*}{\multicolumn{2}{|c|}{$\begin{array}{c}\begin{array}{c}(E) \\
\text { 3rd ventricle } \\
\text { basal } \\
\text { ganglia }\end{array} \\
\text { IICP }\end{array}$}} & \multirow{2}{*}{\multicolumn{2}{|c|}{$\begin{array}{c}\begin{array}{c}(F) \\
\text { Corpus } \\
\text { callosumk }\end{array} \\
\text { IICP }\end{array}$}} \\
\hline & & & & & & & & & & & & \\
\hline & yes & no & yes & no & yes & no & yes & no & yes & no & yes & $n 0,3$ \\
\hline Seizure & 1 & 2 & 1 & 0 & 1 & 0 & 0 & 0 & 1 & 0 & 1 & 0 \\
\hline Mental change & 3 & 5 & 3 & 0 & 0 & 7 & 0 & 1 & 4 & 1 & 1 & 1 \\
\hline \multicolumn{6}{|l|}{$\begin{array}{l}\text { Seizure and mental } \\
\text { change }\end{array}$} & & 0 & & 2 & o & & 0 \\
\hline \multirow[t]{3}{*}{ None } & 3 & 0 & 5 & 6 & 0 & 8 & 0 & 0 & 1 & $\mathbf{0}$ & 0 & 0 \\
\hline & $\overline{10}$ & 10 & 9 & 6 & 2 & $\overline{15}$ & 0 & 1 & 8 & 1 & 5 & 1 \\
\hline & \multicolumn{2}{|c|}{20} & \multicolumn{2}{|c|}{15} & \multicolumn{2}{|c|}{1} & \multicolumn{2}{|c|}{1} & \multicolumn{2}{|r|}{ 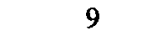 } & \multicolumn{2}{|r|}{. } \\
\hline
\end{tabular}


III

(IICP) IN HEMISPHERIC TUMORS BY LOBAR LOCATION

\begin{tabular}{|c|c|c|c|c|c|c|c|c|c|c|c|}
\hline \multirow{2}{*}{\multicolumn{2}{|c|}{$\begin{array}{c}P-O \\
I I C P \\
\end{array}$}} & \multirow{2}{*}{\multicolumn{2}{|c|}{$\frac{\text { Multilobar }}{\text { IICP }}$}} & \multirow{2}{*}{\multicolumn{2}{|c|}{$\begin{array}{l}T-F \\
I C P\end{array}$}} & \multirow{2}{*}{\multicolumn{2}{|c|}{$\frac{P-T}{I I C P}$}} & \multirow{2}{*}{\multicolumn{2}{|c|}{$\begin{array}{l}\text { Total } \\
\text { IICP }\end{array}$}} & \multicolumn{2}{|c|}{ Total } \\
\hline & & & & & & & & & & \multirow{2}{*}{$\begin{array}{c}\text { Num- } \\
\text { ber }\end{array}$} & \multirow{2}{*}{$\%$} \\
\hline yes & no & yes & no & yes & no & yes & no & yes & no & & \\
\hline 1 & 0 & 2 & 0 & 0 & 1 & 0 & 2 & 26 & 30 & 56 & 31.2 \\
\hline 3 & 0 & 4 & 2 & 1 & 1 & 0 & 0 & 40 & 19 & 59 & 33.0 \\
\hline 2 & 0 & 1 & 0 & 0 & 0 & 0 & 2 & 25 & 18 & 43 & 24.1 \\
\hline 2 & 0 & 2 & 0 & 0 & 0 & 0 & 0 & 16 & 5 & 21 & 11.7 \\
\hline$\overline{8}$ & $\overline{0}$ & 9 & 2 & 1 & 2 & 0 & 4 & $\overline{107}$ & $\overline{72}$ & $\overline{179}$ & $\overline{100.0}$ \\
\hline & & & & & & & & & & & \\
\hline
\end{tabular}

IV

(IICP) IN HEMISPHERIC TUMORS WTH DEEP EXTENSION

\begin{tabular}{|c|c|c|c|c|c|c|c|c|c|c|c|}
\hline \multirow{2}{*}{\multicolumn{2}{|c|}{$\frac{P-O}{I I C P}$}} & \multirow{2}{*}{\multicolumn{2}{|c|}{$\begin{array}{c}\text { Multilobar } \\
\text { IICP }\end{array}$}} & \multirow{2}{*}{\multicolumn{2}{|c|}{$\begin{array}{l}T-F \\
I C P\end{array}$}} & \multirow{2}{*}{\multicolumn{2}{|c|}{$\begin{array}{l}P-T \\
I I C P\end{array}$}} & \multirow{2}{*}{\multicolumn{2}{|c|}{$\frac{\text { Total }}{\text { IICP }}$}} & \multicolumn{2}{|c|}{ Total } \\
\hline & & & & & & & & & & \multirow{2}{*}{$\begin{array}{c}\text { Num- } \\
\text { ber }\end{array}$} & \multirow{2}{*}{$\%$} \\
\hline yes & no & yes & no & yes & no & yes & no & yes & no & & \\
\hline 0 & 0 & 1 & 1 & 1 & 0 & 0 & 0 & 11 & 6 & 17 & 26.6 \\
\hline 3 & 0 & 1 & 3 & 0 & 0 & 0 & 0 & 18 & 3 & 21 & 32.8 \\
\hline 0 & 1 & 0 & 1 & 0 & 0 & 0 & 0 & 14 & 7 & 21 & 32.8 \\
\hline 0 & 0 & 0 & 0 & 0 & 0 & 0 & 0 & 3 & 2 & 5 & 7.8 \\
\hline$\overline{3}$ & $\overline{1}$ & 2 & $\overline{5}$ & 1 & 0 & $\overline{0}$ & $\overline{0}$ & $\overrightarrow{46}$ & $\overline{18}$ & $\overline{64}$ & $\overline{100.0}$ \\
\hline \multicolumn{2}{|c|}{4} & \multicolumn{2}{|c|}{7} & \multicolumn{2}{|c|}{1} & \multicolumn{2}{|c|}{0} & & & & \\
\hline
\end{tabular}

$\mathrm{V}$

(IICP) IN DEEP MIDLINE AND PARAMIDLINE TUMORS

(G)

Primary

sptical nerve

(B) $+(D)$

(C) $+(D)$

(D) $+(E)$

Total

Total

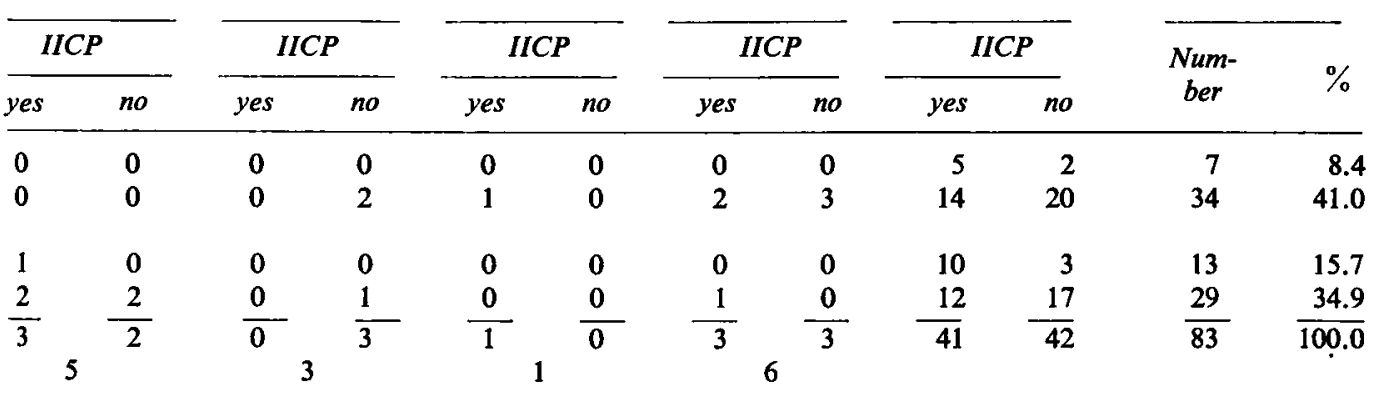


significant relationship between any two of the tumor types of reasonable number in regard to increased intracranial pressure (Table I). On the other hand there are, as mentioned before, ten instances of significant relationship amidst these tumor types in respect of mental changes and seizure. Also when increased intracranial pressure is correlated with seizures and mental changes at the same time, disregarding locations and types of tumors $(\mathrm{df}=3)$, there is no significant relationship between these three variables.

Can the location of the tumors then as put in three broad categories rather than the types be responsible for mental change and seizure (see Table II)? There is no statistically significant relationship between $\mathrm{A}$ and $\mathrm{B}, \mathrm{A}$ and $\mathrm{C}$, and $\mathrm{B}$ and $\mathrm{C}$ locations for mental changes. On the other hand, hemispheric tumors (A location) are apt to produce more seizures than midline and paramidline tumors ( $\mathrm{C}$ location). That is also true of hemispheric tumors with deep extension (B location). Both relationships are highly significant. When the three broad locations are compared in respect to increased intracranial pressure (Table II) there is no statistically significant relationship between $A$ and $B$ locations, nor between $A$ and $C$ locations but there is a significant relationship between $B$ and $C$ locations, $B$ showing more increased intracranial pressure than $C$ location. When it is recalled that it is the same $B$ and $C$ locations that are significantly related for seizures (Table II) and that the B location (hemispheric tumors with deep extensions) produces seizures about 2.5 times as much as the $\mathrm{C}$ location (deep midline and paramidline tumors) the suspicion arises that increased intracranial pressure may have something to do with greater seizure precipitation in $\mathbf{B}$ location than in $\mathbf{C}$ location. But this suspicion proves not to be valid when within the same location category and within the same type the relationship between increased intracranial pressures and seizure on the one hand and increased pressure and mental changes on the other is statistically investigated (these probability values are not shown on the Tables). Only the relationship between increased pressure and seizure is significant in the hemispheric tumors (A location) and also in the midline and paramidline group (C location). It is not significant in the hemispheric tumor group with deep extension (B location). Nor is there any significant relationship between those variables within each of the three tumor types (glioblastoma multiforme, astrocytoma, meningioma). Mental changes and increased intracranial pressure are also entirely unrelated either within each tumor type or within each broad location group. Influence of other factors including the technical factor of grouping cannot be ruled out.

Inspection of Tables III-V which break down the three broad locations into different areas and lobes for seizure, mental change, both seizure and mental change and increased intracranial pressure reveals a wide range of values of each for such areas. Some of the values are large and some are small, on which percentages have been figured but not probabilities.

The types of seizures associated with different areas have been investigated. Seventy-seven temporal lobe tumors with or without extra-temporal extension produced only in $14(18.1 \%)$ temporal lobe seizure phenomena, in $20(26.0 \%)$ grand mal, 
in $10(13.0 \%)$ mixed grand mal and temporal lobe seizure, in $6(7.8 \%)$ Jacksonian and other kinds of "spell" and in $27(35.1 \%)$ no seizure whatsoever. Eighteen tumors with extensive involvement of three or more lobes have been excluded from consideration.

Out of 231 non-temporal tumors $52(23.5 \%)$ produced grand mal seizures, 28 $(12.1 \%)$ sensory or motor Jacksonian seizures, $12(5.2 \%)$ mixed grand mal and Jacksonian seizures, $5(2.2 \%)$ temporal lobe seizure, $4(1.7 \%)$ grand mal and temporal lobe seizure, $11(4.8 \%)$ undetermined spells and $119(51.5 \%)$ no seizure whatsoever.

In regard to the distribution of seizure types for specific non-temporal areas the following information is available. Out of 49 frontal tumors (TablelII), barring motor area but including premotor area, 13 had grand mal, 1 temporal lobe, 2 grand mal and temporal, 8 sensory or motor Jacksonian seizure, 3 grand mal and Jacksonian seizures and 22 no seizures. Out of 31 parietal tumors 10 had Jacksonian, 3 grand mal, 1 Jacksonian and grand mal, 1 undetermined spell and 16 no seizures. Out of 28 motor-parietal tumors 8 had Jacksonian, 4 grand mal, 3 grand mal and Jacksonian, 1 "spell" and 12 no seizures. Out of 21 frontal tumors with deep extension (Table IV), 9 had grand mal, 3 grand mal with Jacksonian, 1 "spell", 1 Jacksonian, 1 temporal lobe and 6 no seizures. Out of 20 olfactory groove and sphenoid ridge tumors (Table V) 4 had grand mal, 2 temporal lobe, 1 grand mal and temporal lobe, 2 "spells" and 11 no seizures. Other locations have too few tumors for specific classification.

\section{DISCUSSION}

Of this series of patients with supratentorial tumors $58.6 \%$ had mental changes. Other workers' figures are: $43 \%$, (Busch, 538 cases), $51.5 \%$ (Soniat, 128 cases), $51 \%$ (Schlesinger, 591 cases), 52.1\% (Schutzenberger, 439 cases). There seems to be a measure of agreement among workers that mental changes occur in the neighborhood of $50 \%$ of tumors. Higher or lower figures may in part be attributable to the criteria for mental change and samples used. The mechanism of these mental changes has been considered differently in the literature. Some think increased intracranial pressure plays no important part (2), others consider it quite important. The present statistical calculations do not suggest any effect of it on mental changes for the whole group divided by type (Table I) though it is intriguing to find that both occur in about the same proportion ( $59.5 \%$ and $58.6 \%$, Table I). Mental changes by our definition, of course, fall outside of the physiological changes like nausea, vomiting and patients' reactions to them. On theoretical grounds and considering the literature it would be difficult to entirely dismiss the effect of increased intracranial pressure. The latter may not be important as a single major factor but one needs to speculate about its adjuvant role. For instance, when broad locations are considered it is found that $B$ location significantly shows more increased pressure than $\mathrm{C}$ location (Table II).

It was hoped that divisions of the tumors under three broad and legitimate locations, regardless of type or increased intracranial pressure, might show that one location produced more mental aberrations than another; but statistically that could not 
be proved. Of course, it is a matter of clinical knowledge that often involvement of hypothalamus, frontal association areas, cingulate gyrus, hippocampus, fornix cause profound mental and behavior aberrations (24). But fine location subdivisions of Tables III-V with small numbers do not justify any definite conclusion. However, there is a tendency for frontal and temporal areas to show more mental changes than parietal areas as found by others $(9,24,30)$. Frontal and temporal areas which have reasonable numbers of tumors with mental changes regardless of increased intracranial pressure (49 vs. 21 and 26 vs. 13 respectively) are, however, not significantly different. Other areas of these two tables and Table $\mathrm{V}$ have insignificant numbers.

On the contrary, one type of tumor, glioblastoma multiforme, produces mental changes significantly more than less malignant tumors such as astrocytoma, oligodendroglioma or both combined (Table I). This agrees with others' findings $(4,30)$. Rapid growth, edema and disruption of normal circulation, and intra- or extracellular biochemical changes may be causes.

For seizures in tumors significant correlations are high. Not only does the whole series show $48.1 \%$ occurrence of seizures but there are significant differences in incidences when different types and some broad locations are considered. Our figures support the literature $(1,6,10,14-17,19,22,23,31)$ that less malignant or slowgrowing tumors like astrocytoma, oligodendroglioma and meningioma produce more seizures than the highly malignant glioblastoma multiforme. Also, deep tumors including pituitary tumors and craniopharyngiomas without extension but excluding olfactory groove and sphenoid ridge tumors are less likely to produce seizures than hemispheric tumors with or without deep extension. Rare pure frontal lobe tumors showing "temporal lobe" seizure phenomenon may involve uncinate fasciculus discharge pathways from frontal to temporal to which attention has been called (25). Only $18 \%$ of temporal lobe tumors (77) with or without extra-temporal extension or increased intracranial pressure produce "temporal lobe" seizure phenomena. About $35 \%$ of temporal lobe tumors have no type of seizure whatsoever. Frontal lobe tumors with or without deep extension and excluding motor-parietal areas produce more grand mal seizures (30 out of 70) than parietal and parieto-occipital tumors (6 out of 48).

\section{ACKNOWLEDGEMENTS}

Acknowledgement is due to the Departments of Neurosurgery, Neuropathology and Neurology.

\section{SUMMARY}

Three hundred and twenty-six supratentorial tumors excluding metastatic lesions have been studied statistically to discover interrelationships between different variables: patients' mental changes, seizures, increased intracranial pressure, tumor type, broad and fine location. Glioblastomas multiformes are more commonly associated with mental changes and less with seizures than astrocytomas, oligodendrogliomas and meningiomas. Strategic location of the tumor also plays an important role. Close to 
$50 \%$ of brain tumors produce seizures and mental aberrations. Increased intracranial pressure per se is not significantly related to the latter; but it is related to seizure phenomenon only in some locations. Deep midline and paramidline tumors as a group produce seizures much less than tumors in the hemisphere with or without deep extension. About one-fourth and one-third of temporal lobe tumors have temporal lobe seizures or no seizures respectively. One-eighth of parietal and parieto-occipital tumors and about half of frontal tumors excluding motor-parietal areas produce grand mal seizures. Individual exceptions need to be considered, also, 46 non-significant relationships out of 71 relationships investigated.

\section{RÉSUMÉ}

Trois cent vingt-six tumeurs supratentorielles, parmi lesquelles des lésions métastasiques étaient exclues, ont fait l'objet d'études statistiques envisageant le but de découvrir des relations mutuelles entre les différentes variables: changements mentaux des malades, crises, pression intracrânienne augmentée, type de tumeur, localisation globale et précise. Des glioblastomes multiformes sont plus souvent associés à des changements mentaux et en moindre mesure avec des crises que des astrocytomes, oligodendrogliomes et méningiomes. La localisation de la tumeur joue aussi un rôle important. Près de $50 \%$ des tumeurs cérébrales provoquent des crises et des aberrations mentales. Une augmentation de la pression intracrânienne n'est pas en relation, de façon significatıve, avec ces derniers cas; mais elle est à rapporter au phénomène crise dans certaines localisations. Le groupe des tumeurs médianes et paramédianes produit bien moins de crises que des tumeurs dans l'hémisphère avec ou sans extension en profondeur. A peu près un quart et un tiers des tumeurs du lobe temporal ont des crises du lobe temporal ou, respectivement, pas de crises. Un huitième des tumeurs pariétales et pariéto-occipitales et la moitié environ des tumeurs frontales à l'exclusion de l'ère moto-pariétale provoque des crises de grand mal. Des exceptions individuelles sont à considérer et, de même, 46 relations non significatives parmi les 71 relations qui ont été étudiées.

\section{REFERENCES}

1. Alajouanine, T., Rondot, P., Laplane, D. and Castaigne, P., Tumoral epilepsy, Rev. Prat., 9 (1959) 1409-1412.

2. Arseni, C. And Samitca, D. C., Some remarks on epilepsy in brain tumors, Zbl. Neurochir., 17 (1957) 369-377.

3. Bingley, T., Mental symptoms in temporal lobe epilepsy and temporal lobe gliomas. Acta psychiat. scand., Suppl. 120 (1958).

4. Busch, E., Psychical symptoms in neurosurgical diseases, Acta psychiat. (kbh.), 15 (1940) 257-290.

5. Cecotto, C., Briani, S. ANd Frugoni, P., Epilepsy in cerebral tumors; considerations in 839 cases, Riv. Neurol., 26 (1956) 277-294.

6. Daly, D., MACCARTY, C. S. AND BICKFORD, R. G., Seizures in patients with gliomas of cerebral hemispheres, Trans. Am. Neurol. Ass., 75 (1950) 159-161.

7. Elvidge, A. R. AND MARTinez-Coll, A., Long-term follow-up of 106 cases of astrocytoma, J. Neurosurg., 8 (1956) 318-331. 
8. Fisher-Williams, M., Last, S. L., Lyberi, G. and Northfield, D. W., Clinico-electroencephalographic study of 128 gliomas and 50 intracranial metastatic tumors, Brain, 85 (1962) 1-46.

9. Freeman, D. G., Petrohelos, M. A. and Henderson, J. W., Neurologic symptoms and signs in 347 cases of verified tumor, Neurology (Minneap.), 3 (1953) 437-452.

10. FurLow, L. T. AND SACHS, E., The occurrence of convulsions in intracranial tumors, Sth. Surg., 5 (1936) 179-192.

11. Gonzalez, D. AND Elvidge, A. R., On the occurrence of epilepsy caused by astrocytoma of the cerebral hemispheres, J. Neurosurg., 19 (1962) 470-482.

12. Guidetti, B. and Carloni, G., Psychic disorders in tumors of temporal lobe; clinical study, Riv. Pat. nerv. ment., 74 (1953) 259-301.

13. Hermann, K. and Stromgren, E., Paroxysmal disturbances of consciousness in verified localized brain affections, Acta psychiat. (kbh.), 19 (1944) 175-194.

14. Hoefer, P. F. A., Schlesinger, E. B. ANd Pennes, H. H., Seizures in patients with brain tumors, Epilepsy Ass. Res. nerv. Dis. Proc., Vol. 26, Williams and Wilkins Co., Baltimore, 1947.

15. KIRSTEIN, L., Epilepsie bei intrakraniellen expansiven Prozessen, Acta med. scand., 110 (1942) 56-68.

16. LaPlane, D., Tardy epilepsy and tumoral epilepsy, Bull. Soc. Med., Paris, 75 (1959) 968-974.

17. Lund, M., Epilepsy in association with intracranial tumor, Acta psychiat. scand., Suppl. 81 (1952) 3-149.

18. Militichap, J. G., Bickford, R. G., Miller, R. H. and Beckus, R. E., Electroencephalography in children with intracranial tumors and seizures, Neurology (Minneap.), 12 (1962) 329-336.

19. Paillas, J. E., Bonnal, J. and Corriol, J., Epilepsy of cerebral tumors: study of apropos of 170 epileptogenic tumors, Rev. Neurol., 88 (1953) 18-29.

20. Parker, H. L., Epileptiform convulsions. The incidence of attacks in cases of intracranial tumor, Arch. Neurol. Psychiat., 23 (1930) 1032-1041.

21. Penfield, W. and Erickson, T. C., Epilepsy and Cerebral Localization, Charles C. Thomas, Springfield, 1941.

22. Penfield, W., Erickson, T. C. and Tarlov, I., Relation of intracranial tumors and symptomatic epilepsy, Arch. Neurol. Psychiat., 44 (1940) 300-315.

23. Pilcher, C. AND Parker, E. F., A study of convulsions associated with verified focal intracranial lesions, Zbl. Neurochir., 3 (1938) 330-341.

24. SCHLesinger, B., Mental changes in intracranial tumors and related problems, Confin. neurol., 10 (1950) 225-263, 322-355.

25. Schneider, R. C., Crosby, E. C., Bagchi, B. K. and Calloun, H. D., Temporal or occipital lobe hallucinations triggered from frontal lobe lesions, Neurology (Minneap.), 11 (1961) 172-179.

26. SChuster, P., Psychische Störungen bei Hirntumoren, Enke, Stuttgart, 1902.

27. Schutzenberger, P., HeCaen, H. AND De Ajuriaguerra, J., Relative influence of intracranial hypertension and localization in mental disorders associated with cerebral tumors, Rev. Neurol., 94 (1956) 259-263.

28. Shefer, D. G. AND Beliaev, IuI., Epileptic seizures and histological structure of brain tumors, Vop. Neirokhir, 25 (1961) 43-46.

29. Sherman, 1. J., Symptoms and signs in 100 cases of verified brain tumor, Conn. Med., 25 (1961) 484-485.

30. Soniat, T. L. L., Psychiatric symptoms associated with intracranial neoplasms, Amer. J.Psychiat., 108 (1951) 19-22.

31. White, J., Liv, C. T. AND Mixter, W. J., Focal epilepsy, New Engl. J. Med., 238 (1948) 891-899.

Epilepsia, 5 (1964) 166-176 